\title{
The Association of Night Shift Work with the Development of Breast Cancer in Women
}

\author{
P. I. J. Moukangoe, M. S. Jansen van Rensburg \\ Independent Consultants, Johannesburg, South Africa \\ Email: drphasoane@live.co.za, madrijvr@gmail.com
}

Received 21 December 2014; accepted 14 January 2015; published 20 January 2015

Copyright (C) 2015 by authors and Scientific Research Publishing Inc.

This work is licensed under the Creative Commons Attribution International License (CC BY). http://creativecommons.org/licenses/by/4.0/

(c) (i) Open Access

\section{Abstract}

Breast cancer is a serious public health concern in South Africa and globally. It is estimated that one in seven South Africans will develop cancer in their lifetime. According to a case-controlled study, $80 \%$ of cancer cases are thought to be due to external, non-inherited factors, which could potentially have been prevented. The objectives of the current case-control study were: 1) to determine the relationship between night shift work and the development of breast cancer; 2) to explore the relationship between night shift work and other types of cancer; 3 ) to explore any difference between night shift work and breast cancer, and night shift work and other types of cancer. A total of 106 research participants were selected using non-probability, convenience sampling methods and interviewed using a structured questionnaire. Seventy-two (68\%) of the women who were interviewed were black, while $32 \%(n=35)$ were white. Of the 106 research participants, $82 \%(n=87)$ had a history of being employed, while $18 \%(n=19)$ had never been employed. Analysed data showed that $29 \%(n=31)$ of the women had a history of working night shift. Of the 31 research participants who reported having worked night shift, $90 \%(\mathrm{n}=28)$ had actually done rotating shift work, rather than regular night shift work. The odds ratio of working night shift was found to be $1.24(\mathrm{OR}=1.24, p=0.615)$ higher in breast cancer research participants compared to research participants diagnosed with other types of cancer-odds ratio of $0.80(p=0.610)$. For rotational work, the OR was 1.445 , indicating a higher risk than for shift work. It is recommended that the relationship between working night shift and breast cancer risk be explored further through cross-sectional and cohort studies.

\section{Keywords}

Breast Cancer, Cancer, Night Shift, Rotating Shift, Regular Night Shift, Parity, Genetic Predisposition 


\section{Introduction}

Cancer is considered one of the major killers throughout the world, including South Africa. Breast cancer is the commonest cause of cancer death in women worldwide. Breast cancer rates vary about five-fold around the world, but they are increasing in regions that until recently had low rates of this disease. For example, in China, rates have traditionally been low in comparison with Western countries [1] [2]. The South African Medical Research Council (2013) estimated that one in seven South Africans will develop cancer in their lifetime [3]. According to Urban, and coworkers, $80 \%$ of cancer cases are thought to be due to external, non-inherited factors, which could potentially have been prevented [4]. According to the 2000-2001 National Cancer Registry (NCR) Report 2000-2001 women have a lifetime risk (LR) of 1 in 8 of getting cancer, with breast cancer having an LR of 1 in 29 [5].

The effect of night shift work on breast cancer has received increasing interest since a panel of the International Agency for Research on Cancer (IARC) declared, in 2007, that "shift work that involves circadian disruption is probably carcinogenic to humans" [6]. This designation of night shift work as a potential cause of cancer by the IARC was based mainly on animal experimental studies that noted an increase in the incidence of progression of tumors, including breast cancer, in animals exposed to light at night [6] [7]. The evidence is strongest for breast cancer, although the risk of prostate and colorectal cancer may also be increased by working night shift [8].

Exposure to light at night, including disturbance of the circadian rhythm, has been suggested as a risk factor for breast cancer. Research has shown that melatonin plays an integral part in the development of tumours. Hence, people who engage in night shift work may exhibit altered nighttime melatonin levels and reproductive hormone profiles that could increase the risk of breast cancer [8]. However, this conclusion was based on evidence from animal studies but limited human studies.

Until now, only a few epidemiological studies have evaluated breast cancer risk from night shift work. Most of these studies have methodological flaws, especially concerning the assessment of light exposure [9]. Even though these studies were methodologically flawed, the evidence is strong enough to have led the Danish National Board of Industrial Injuries to compensate 38 women with breast cancer who previously worked night shifts for at least 20 years [8]. However, the need for high quality epidemiological cancer research still exists, and several studies on different aspects of breast cancer, work schedules, light exposure and melatonin levels are ongoing [9].

\section{Methods}

This observational analytical case-control study of data obtained through structured questionnaires included 106 women (between 18 and 80 years of age), who had been diagnosed and treated for cancer in the Vaal Triangle area in Vereeniging, South Africa, from April 2013 to July 2013. Fifty-seven women with breast cancer were selected and compared with forty-nine control group participants (women) with other types of cancer. Study purposes and processes were explained during the consent process and written participation and information consent was obtained.

Interviews to assess the association of night shift working and development of breast cancer were conducted after obtaining the written informed consent. The interviews were conducted with the help of research assistants from the Cancer Association of South Africa (CANSA) in the Vaal Triangle area. Research assistants were trained on ethical research behaviour and how to conduct interviews, including being given an in-depth understanding of the questions being asked.

Data collected included age at diagnosis, age at menarche, race, employment status, history of smoking, history of alcohol abuse, use of contraceptives, genetic predisposition, parity, number of births (both live and dead), weight, number of years of employment, hours worked night per shift (at least 8 hours per night), number of nights worked night shift per week, and number of years worked night shift.

The population for the study was 150 female cancer patients, between the ages of 18 and 80, registered with the CANSA office in the Vaal Triangle area. A sample of 96 research participants was calculated, based on a $95 \%$ confidence level and confidence interval of 6 . For non-response, $10 \%$ was added to the sample size. So, the final sample size recruited for the study was 106. This sample was adequate for the study and valid to perform statistical tests. 


\subsection{Ethical Considerations}

Ethical permission for the study was obtained from the ethics committee of the Department of Health Studies of the University of South Africa.The research proposal for this study also went through CANSA to ensure ethical considerations were met and that there was face-validity. All women between the ages of 18 and 80 diagnosed with cancer, and registered with the CANSA Vaal Triangle offices were included in the sampling frame to avoid bias.

Research participants voluntarily agreed to participate in the study and written information consent was obtained from all participants. Participants were informed that they could withdraw from the study at any point and that, if they so desired, their questionnaire would be destroyed. Anonymity and confidentiality were assured and maintained throughout the study. To ensure confidentiality, no form of identifier was used in the questionnaires, except the name of the research assistant. Interviews were conducted immediately after obtaining the written informed consent, or scheduled for the next convenient day thereafter. There was only one person who did not want to participate, and this was because no monetory incentive was given for participation.

\subsection{Data Analysis}

Epi-info 7 computer software was used to perform statistical analysis. The results were summarised using descriptive statistics, expressed as frequency distributions and percentages for variables of interest. Association between the variables was tested by means of contingency tables and the chi-square $\left(\chi^{2}\right)$. Odds ratios (OR) with 95\% confidence intervals were calculated. In this study, the OR was the main ratio used as the risk ratio (RR) is not relevant for case control studies. The odds ratio compares the odds of exposure to the factor of interest among cases to the odds of exposure to the factor among controls.In a case-control study like this one, a predetermined number of cases and controls are selected, so their numbers may not reflect the proportions of diseased and non-diseased in the population. It is for this reason that the risk ratio, relative risk and risk difference were not calculated. Contingency tables and Chi-square were computed to describe the statistical significance of the relationship between night shift work and the development of breast cancer.

\section{Results}

A total of 106 cancer patients were interviewed using structured questionnaires, which means the response rate was $100 \%$. The age of research participants ranged from younger than 18 to older than 75 years. Sixty-seven percent $(n=71)$ of the research participants were in the age group 36 - 65 years. There was no statistical significant difference between the two groups (case and control) for age distribution ( $p=0.745$ ).

With regard to racial distribution, the majority of research participants were black (African) women (67\%, $n=$ $71)$ and whilst $30 \%(n=35)$ were white. There was no statistically significant difference between the two racial groups with regard to cases and controls $(p=0.303)$. Table 1 below depicts the socio-demographic characteristics of the research participants.

Table 1. Socio-demographic characteristics of research participants.

\begin{tabular}{cccc}
\hline & \multicolumn{3}{c}{ Race } \\
\cline { 2 - 4 } & Black & White & Total \\
Age & & & \\
Younger than 18 & 1 & - & 1 \\
$18-25$ & 3 & - & 3 \\
$26-35$ & 9 & 4 & 13 \\
$36-45$ & 16 & 2 & 18 \\
$46-55$ & 25 & 9 & 34 \\
$56-65$ & 9 & 9 & 18 \\
$66-75$ & 7 & 6 & 6 \\
Older than 75 & 2 & 4 & 8 \\
Marital status & & & 51 \\
Divorced & 6 & 2 & 23 \\
Married & 27 & 24 & 24 \\
Single & 22 & 1 & \\
Widowed & 17 & 7 & \\
\hline
\end{tabular}


The majority of the research participants $(86 \%, \mathrm{n}=92)$ reported menarche between 11 and 15 years of age with the mean and median age being 14 years. The distribution of age at first mense was similar for the cases and controls $(\mathrm{p}=0.0899)$.

With regard to genetic predisposition, 57\% $(n=60)$ of the research participants reported a history of cancer in their family. Forty percent $(n=23)$ of breast cancer cases reported having a family history of breast cancer, whilst $24 \%(n=15)$ of breast cancer cases reported having a family history of other types of cancer. Of the research participants with other types of cancer, $16 \%(n=8)$ reported having a family history of breast cancer, whilst $29 \%(n=14)$ reported a family history of other types of cancer.

Fourteen percent of the beast cancer cases reported sleeping with a light on at night, whilst $20 \%$ of controls reported sleeping with a light on at night. The researcher then calculated both the odds ratio and Chi-square. The odds ratio was 0.637 . The chi-square test also showed no statistical difference between the control and cases, $\chi^{2}$ of $0.759(95 \% \mathrm{CI}=0.2295$ to 1.7665$)$. The $\mathrm{p}$-value is 0.384 . This result is not statistically significant at $\mathrm{p}<0.05$.

In total, 86 participants reported having been employed, the majority of whom started working at between 17 and 20 years of age. The age at first employment was similar for the two groups $(p=0.676)$. Table 2 shows the distribution of research participants according to the age they started working.

With regard to the relationship between working night shift and the development of breast cancer, nearly a third $(31.58 \%, \mathrm{n}=18)$ of research participants in the breast cancer group indicated ever having worked night shift, while $27.08 \%$ of the other types of cancer group also reported having ever worked night shift. Contingency tables were used for statistical tests. The calculated odds ratio was 1.24. Thus, women who work night shift have a $24 \%$ higher chance of developing breast cancer than the participants with other types of cancer. We are $95 \%$ confident that the true odds ratio is between 0.5328 and 2.8982. Because this value spans 1 , the increased odds (OR 1.2426) of working night shift among research participants with breast cancer do not reach statistical significance. This was further indicated by the Chi-square calculation, which gave a p-value of 0.6149 . This value is very low. Hence, the relationship between exposure to working night shift and developing breast cancer was not considered to be statistically significant. Thus, working night shift probably does not lead to a higher risk of developing breast cancer. Table 3 and Table 4 show the statistical calculations performed.

Table 2. Ageat first employment.

\begin{tabular}{|c|c|c|c|c|}
\hline \multirow[b]{2}{*}{ Age } & \multicolumn{2}{|c|}{ Cases } & \multicolumn{2}{|c|}{ Control } \\
\hline & Frequency & Percentage & Frequency & Percentage \\
\hline 15 & 1 & $2 \%$ & 0 & $0 \%$ \\
\hline 16 & 1 & $2 \%$ & 1 & $2.5 \%$ \\
\hline 17 & 1 & $2 \%$ & 5 & $13 \%$ \\
\hline 18 & 5 & $11 \%$ & 6 & $15 \%$ \\
\hline 19 & 6 & $13 \%$ & 5 & $13 \%$ \\
\hline 20 & 10 & $21 \%$ & 4 & $10 \%$ \\
\hline 21 & 1 & $2 \%$ & 1 & $2.5 \%$ \\
\hline 22 & 2 & $4 \%$ & 3 & $8 \%$ \\
\hline 23 & 1 & $2 \%$ & 2 & $5 \%$ \\
\hline 25 & 1 & $2 \%$ & 5 & $13 \%$ \\
\hline 26 & 11 & $24 \%$ & 1 & $2.5 \%$ \\
\hline 30 & 2 & $4 \%$ & 3 & $8 \%$ \\
\hline 35 & 4 & $9 \%$ & 1 & $2.5 \%$ \\
\hline 36 & 1 & $2 \%$ & 1 & $2.5 \%$ \\
\hline 37 & & & 1 & $2.5 \%$ \\
\hline TOTAL & 47 & $100 \%$ & 39 & $100 \%$ \\
\hline
\end{tabular}


Table 3. Odds ratio for night shift work.

\begin{tabular}{cccc}
\hline Parameters & Point estimate & \multicolumn{2}{c}{ 95\% confidence interval } \\
\hline & & Lower & Upper \\
\hline Odds Ratio & 1.24 & 0.53 & 2.89 \\
Risk Ratio & 1.08 & 0.72 & 1.63 \\
Fisher Exact & & 0.49 & 3.18 \\
\hline
\end{tabular}

Table 4. Chi-square calculations.

\begin{tabular}{ccccc} 
& Value & Degree of freedom & $\mathbf{1}$ Tailed P & 2 Tailed P \\
\hline Chi-square & 0.25 & 1 & & 0.61 \\
Fisher exact & & & 0.39 & 0.67 \\
No of valid cases & 105 & & \\
\hline
\end{tabular}

A total of 28 women reported they had done rotating shift work, compared to only one woman who reported to have worked night shift only. The OR for the relationship between working rotating shifts and the development of breast cancer was 1.445 , which was found to be small to determine the statistical significance of the relationship. Chi-square was also computed to ascertain the relationship between the two variables. The Chisquare calculation was not statistically significant with a value of 0.630 ( $\mathrm{df}=\mathrm{n}-1$, $\mathrm{p}$-value $=0.427$ ). This value also showed no statistically significant relationship between working rotating shifts and the development of breast cancer.

\section{Discussion}

The study was carried out to describe the relationship between night shift work and the development of breast cancer. For the purposes of the study, 106 women were interviewed. Of the 106 research participants interviewed, 57 were patients with breast cancer and 49 with other types of cancers (forming the control group). Seventy-one were black women and 35 were white women. Forty-one (39\%) of women diagnosed with breast cancer were black and16 (15\%) were white. For those with other types of cancer, 28\% (n = 30) of the women were black, whilst $17 \%(n=18)$ were white. Sixty-seven percent $(n=71)$ of the research participants were aged between 36 and 65 years.

The variables which influence the development of breast cancer, were similar across the cases and controls. The distribution of variables such as age at first menses, age at birth of first child, history of breast feeding and parity were similar across the cases and control group. Testing of genetic predisposition variables followed the general finding of other studies of a high reported family history with $40 \%$ of breast cancer cases in this study reporting a family history of breast cancer, compared to only $16 \%$ of the control group.

Scheer and co-authors, demonstrated that shift work is a risk factor for many health problems [10]. To maintain the demand for improved efficiency in some industries, there has been an increasing drive towards the use of shift workers. Costa also indicated that women can be more vulnerable to shift-work because of their more complex circadian rhythm and extra demands related to family life [11]. Other studies have analysed the relationship between shift-work and the development of breast cancer.

Of the research participants in this study who reported having worked night shift $(\mathrm{n}=31)$, the majority (90\%, $\mathrm{n}=28$ ) had worked rotating shifts, while only $10 \%(\mathrm{n}=3)$ reported having worked either regular night or evening shift. The odds of having ever worked night shift are 1.24 higher in breast cancer cases compared to research participants diagnosed with other types of cancer for whom it was $0.80(p=0.610)$.

Eighteen (32\%) of breast cancer cases reported working night shift. In terms of best describing participants night shift work patterns, the study found that about 30\% of breast cancer cases actually worked rotating shifts, rather than regular night shift. Only $1.7 \%$ of breast cancer cases reported regular night shift work. In the control group, this was more evenly distributed with $22 \%$ of the control group reporting night shift working, whilst $24 \%$ $(n=12)$ reported rotational shift work. 
The odds of working rotating shifts are 1.4 greater in breast cancer research participants than those with other types of cancer, for whom it is $0.79(\mathrm{p}=0.42)$. A larger number of research participants reported working rotating shifts than only night shift, and the odds ratio was higher for rotating shift work than night shift (including both rotating and regular night shift). However, working rotating shifts had no statistically significant relationship to the development of breast cancer, even though the odds in favour of development of breast cancer in women who worked rotating shift were greater than those with other types of cancer. There was also no statistically significant relationship between working regular night and evening-shifts and the development of breast cancer. The odds ratio found in this study is slightly lower than that reported by Megdal and co-authors who found a summary relative risk of (RR) 1.48 (95\% CI 1.36 - 1.91) in a meta-analysis of the data on night shift work and breast cancer [12].

The current study demonstrated that there was no statistically significant association between women engaged in night shift work and the development of breast cancer. However, the odds of working night shift among breast cancer cases are 1.24 greater than those for the control group (OR $=0.80)$, and 1.4 for rotational shift work. While the estimated odds ratio in this study is larger for breast cancer cases there was no statistically significant difference between the breast cancer cases and the control group $\left(\chi^{2}=0.25\right.$, p-value $\left.=0.61\right)$. When classifying night shift work as a "probable carcinogen" the IARC working group noted that a number of existing studies in humans were limited to nurses [6]. This study was not limited to nurses or health workers as the relationship between night shift work duration and breast cancer risk was similar for those employed in health and non-health occupations [13]. The current study did not consider occupational category to be a confounder.

A study conducted by Lie and co-authors found that there was an increase in the risk of breast cancer among women working night shift for more than 30 years [14]. The current study tested the relationship between night shift work and breast cancer in women who had worked night shift between 5 and 20 years. Schernhammer and co-authors reported an increased breast cancer risk for postmenopausal women following more than 30 years of rotating shift work [15], whilst Schernhammer and co-authors (2006) reported a breast cancer risk in premenopausal women working rotating-shift for more than 20 years [16]. Therefore, the results of this may be inconsistent with results of other studies due to the length of occupation (more than 20 years) that the women were exposure [15] [16]. The findings of the current study are, however, consistent with a population-based case-control study which showed a non-significantly increased risk for those engaging in shift work for over 20 years [17]. The inconsistency of findings from these studies may be explained, in part, by variations in definition of shiftwork and study design, potential recall bias, focus on a single profession versus multiple professions, and incomplete adjustment for confounding factors [18].

In conclusion, the results of the current study demonstrate no statistically significant relationship between night shift work and the development breast cancer. Other studies found an association between breast cancer development and night shift work in premenopausal women who work rotating shifts for more than 20 years, and postmenopausal women who work rotating shifts for more than 30 years [15] [16]. Industry's attempts to improve their efficiency through an increasing drive towards using rotating shifts, women getting more involved in industries and work previously reserved for men, coupled with the vulnerability of women's health to shiftwork, makes an understanding of the work patterns which increase the risk for breast cancer vital. We need to understand how night shift work influences the breast cancer pathway, so as to inform policy makers about possible preventative and even curative measures in the fight against this potentially fatal condition.

\section{Limitations of the Study}

This study encountered some limitations, including representativeness of the research participants, and the study sample size.

For the purposes of this study, the researcher used a non-probability sampling method, as it is difficult to use probability sampling and select research participants randomly in a case-control design. Because the study population consisted of women at one CANSA office, the results may not be generalisable to all women with breast cancer. However, they can be used as a foundation for more sensitive research designs.

Even though the researcher focused on testing participants' perceived views perception testing, the data-collection instrument, which was a structured questionnaire with closed-ended questions, might have limited research participants' ability to express their personal views. Conducting a thorough literature review, did ensure that the researcher included a broad choice of responses for a number of questions. 


\section{Conclusion}

Since breast cancer is becoming a major cause of death, preventing or limiting exposure to known carcinogens appears to be a logical way to reduce the incidence of breast cancer, and cancer in general. With the increasing incidence of breast cancer, there is a real need to consider taking all appropriate and effective measures against proven links to breast cancer, with the aim of reducing the burden on healthcare systems [19]. Thus, it is necessary to modify public health activities, such as campaigns, to improve the understanding of the consequences and risks of night shift work and how to minimise the development of breast cancer.

\section{References}

[1] Fan, L., Zheng, Y., Yu, K.D., Liu, G.Y., Wu, J., Lu, J.S., Shen, K.W., Shen, Z.Z. and Shao, Z.M. (2009) Breast Cancer in a Transitional Society over 18 Years: Trends and Present Status in Shanghai, China. Breast Cancer Research and Treatment Journal, 117, 409-416. http://dx.doi.org/10.1007/s10549-008-0303-z

[2] Key, T.J., Verkasalo, P.K. and Banks, E. (2001) Epidemiology of Breast Cancer. Lancet Oncology, 2, $133-140$. http://dx.doi.org/10.1016/S1470-2045(00)00254-0

[3] South African Medical Research Council (2013) What Are the Top Causes of Death Due to Cancer in South Africa? Burden of Disease Research Unit. http://www.mrc.ac.za/bod/faqcancer.htm

[4] Urban, M., Banks, E., Egger, S., Canfell, K., O’Connell, D., Beral, V. and Sitas, F. (2012) Injectable and Oral Contraceptive Use and Cancers of the Breast, Cervix, Ovary, and Endometrium in Black South African Women: Case-Control Study. PLOS Medicine, 9, 1-11.

[5] Cancer Association of South Africa (2010) Overview of the Latest National Cancer Registry Statistics. Leading Five Female Cancers in South Africa. http://www.cansa.org.za/womens-health/

[6] Straif, K., Baan, R., Grosse, Y., Secretan, B., Ghissassi, F., Bouvard, V., Altieri, A., Benbrahim-Tallal, L. and Cogliano, V. (2007) Carcinogenicity of Shift-Work, Painting, and Fire-Fighting. Lancet Oncology, 8, 1065-1066. http://dx.doi.org/10.1016/S1470-2045(07)70373-X

[7] Stevens, R.G. (2009) Light-at-Night, Circadian Disruption and Breast Cancer: Assessment of Existing Evidence. International Journal of Epidemiology, 38, 963-970. http://dx.doi.org/10.1093/ije/dyp178

[8] Wise, J. (2009) Danish Night Shift Workers with Breast Cancer Awarded Compensation. British Medical Journal, 338, 1152.

[9] Hansen, J. (2006) Risk of Breast Cancer after Night- and Shift Work: Current Evidence and Ongoing Studies in Denmark. Cancer Causes Control, 17, 531-537. http://dx.doi.org/10.1007/s10552-005-9006-5

[10] Scheer, F.A., Hilton, M.F., Mantzoros, C.S. and Shea, S.A. (2009) Adverse Metabolic and Cardiovascular Consequences of Circardian Misalignment. Proceedings of the National Academy of Science United States of America, 106, 4453-4458. http://dx.doi.org/10.1073/pnas.0808180106

[11] Costa, G. (2001) Shift-Work Health Consequences. In: Karwowski, W., Eds., International Encyclopedia of Ergonomics and Human Factors, Volume 2, Taylor Francis, London, 1359-1360.

[12] Megdal, S.P., Kroenke, C.H., Laden, F., Pukkala, E. and Schernhammer, E.S. (2005) Night Work and Breast Cancer Risk: A Systematic Review and Meta-Analysis. European Journal of Cancer, 41, 2023-2032. http://dx.doi.org/10.1016/j.ejca.2005.05.010

[13] Grundy, A., Richardson, H., Burstyn, I., Lohrisch, C., SenGupta, S.K., Lai, A.S., Lee, D., Spinelli, J.J. and Aroson, K.J. (2013) Increased Risk of Breast Cancer Associated with Long-Term Shift Work in CANADA. Occupational and Environmental Medicine, 70, 831-838.

[14] Lie, J.A., Roessink, J. and Kjaerheim, K. (2006) Breast Cancer and Night Work among Norwegian Nurses. Cancer Causes Control, 17, 39-44. http://dx.doi.org/10.1007/s10552-005-3639-2

[15] Schernhammer, E.S., Laden, F., Speizer, F.E., Willet, W.C., Hunter, D.J., Kawachi, I. and Colditz, G.A. (2001) Rotating Night Shifts and Risk of Breast Cancer in Women Participating in the Nurses’ Health Study. Journal of National Cancer Institute, 93, 1563-1568. http://dx.doi.org/10.1093/jnci/93.20.1563

[16] Schernhammer, E.S., Kroenke, C.H., Laden, F. and Hankinson, S.E. (2006) Night Work and Risk of Breast Cancer. Epidemiology, 17, 108-111. http://dx.doi.org/10.1097/01.ede.0000190539.03500.c1

[17] Pesch, B., Harth, V., Rabstein, S., Baish, C., Schiffermann, M., Bonberg, N., Heinze, E., Spickenheuer, A., Justenhoven, C., Brauch, H., Hamann, U., Ko, Y., Straif, K. and Bruning, T. (2010) Night Work and Breast Cancer-Results from the German GENICA Study. Scandanavian Journal of Work, Environment and Health, 36, 134-141.

[18] Anjoeka, P., Bu-Tian, J., Xiao-Ou, S., Shouzheng, X., Gong, Y., Hong-Lan, L., Nathaniel, R., Yu-Tang, G., Wei, Z. and Wong-Ho, Chow. (2010) Night Shift Work and Breast Cancer Risk in a Cohort of Chinese Women. American 
Journal of Epidemiology, 171, 953-959. http://dx.doi.org/10.1093/aje/kwq029

[19] Groot, M.T., Baltussen, R., Uyl-de Groot, C.A., Anderson, B.O. and Hortobagyi, G.N. (2005) Costs and Health Effects of Breast Cancer Interventions in Epidemiologically Different Regions of Africa, North America, and Asia. 2nd Biennial Global Summit Consensus Conference on International Breast Health Care, Bethesda, 12-15 January 2005, 581-590. 
Scientific Research Publishing (SCIRP) is one of the largest Open Access journal publishers. It is currently publishing more than 200 open access, online, peer-reviewed journals covering a wide range of academic disciplines. SCIRP serves the worldwide academic communities and contributes to the progress and application of science with its publication.

Other selected journals from SCIRP are listed as below. Submit your manuscript to us via either submit@scirp.org or Online Submission Portal.
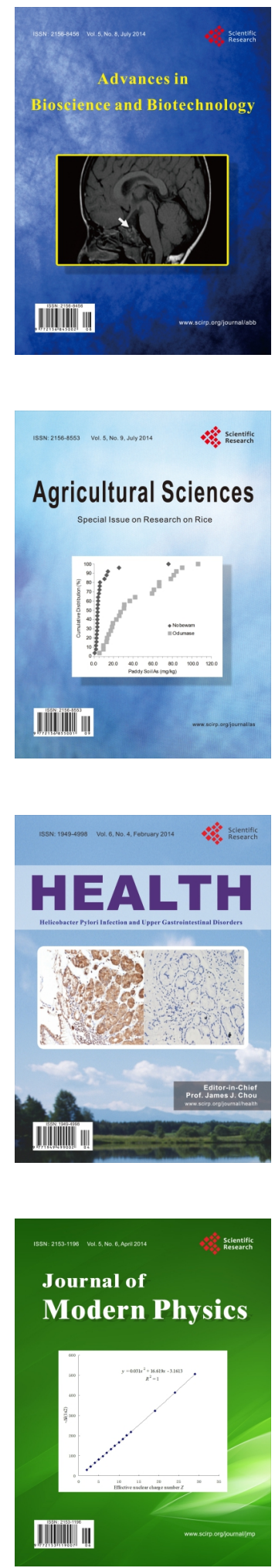
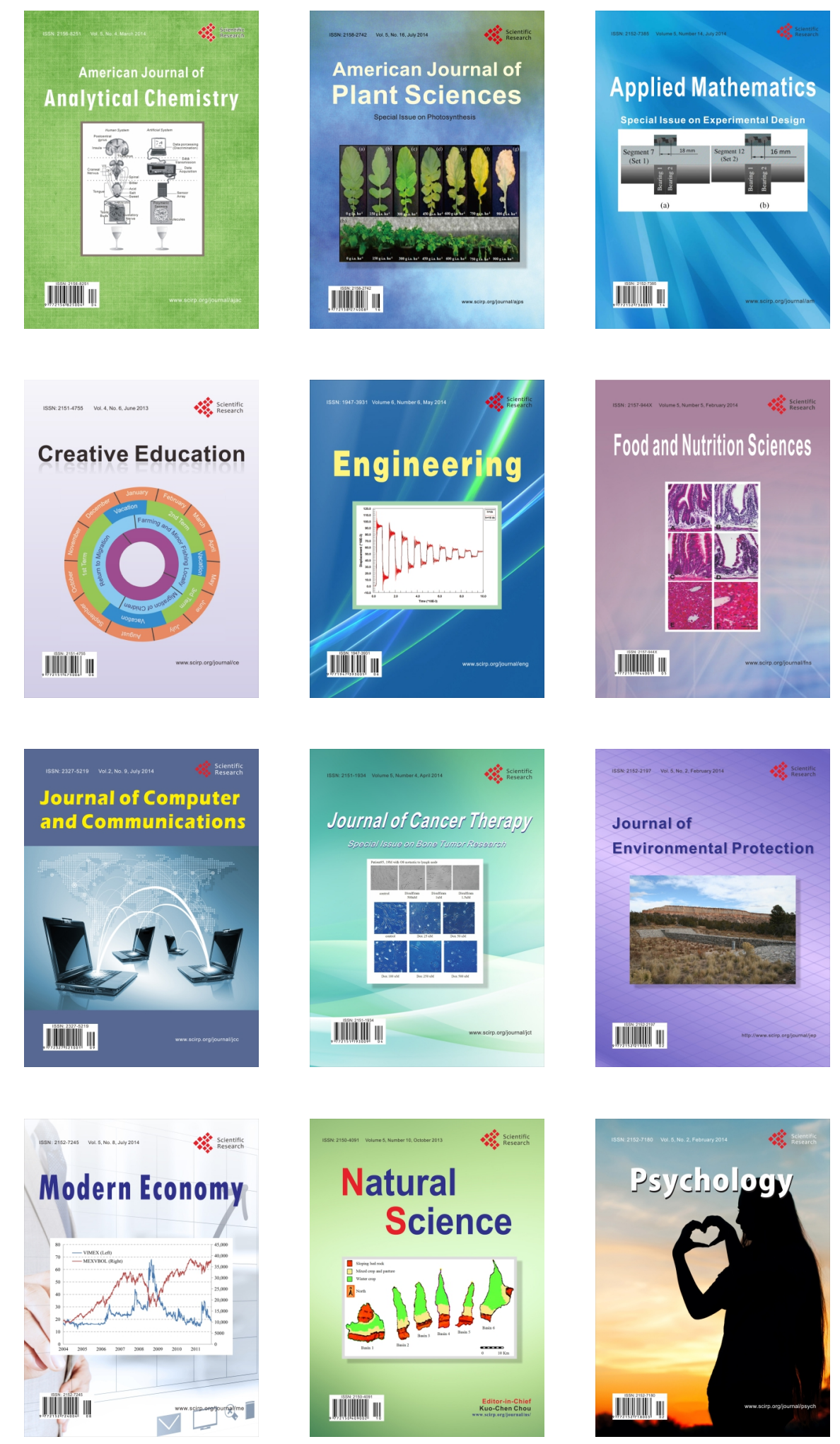